\title{
Editorial Article
}

\section{Plagiarism in Scientific Publications}

\author{
Peter R. Mason
}

Biomedical Research \& Training Institute, Harare, Zimbabwe

J Infect Developing Countries 2009; 3(1):1-4.

Received 18 February 2009 Accepted 25 February 2009

Copyright () 2009 Mason. This is an open access article distributed under the Creative Commons Attribution License, which permits unrestricted use, distribution, and reproduction in any medium, provided the original work is properly cited.

\section{Plagiarism in Scientific Publications}

The US Federal Government defines research misconduct as the "fabrication, falsification or plagiarism in proposing, performing or reviewing research or in reporting research results" [1]. Plagiarism has itself been defined in many ways, but a common theme is "the deliberate or reckless use of someone else's thoughts, words or ideas as one's own, without clear attribution of their source" [1-3]. In scientific writing, plagiarism is regarded as a serious breach of ethics. Authors have a responsibility to ensure that they make due acknowledgement every time they use the ideas or words of others. Editors of scientific journals also have a responsibility to discourage plagiarism, as well as other forms of misconduct, and to be aware of the effects that such misconduct may have on the validity of articles they publish [4].

Avoiding plagiarism is not always easy. Research in science is based on a thorough appreciation of the current state of knowledge on the subject of the research. It is inevitable that some of a writer's own thoughts and ideas will correlate very closely with those expressed by others. This then puts a great deal of responsibility on authors to ensure that "accidental plagiarism" does not arise when they submit a paper describing the outcomes of their research. That means that authors must take every care to ensure that the words used in writing an article are their own words and not the words of others. Some academic institutions regard even "unintentional plagiarism" as being a breach of ethics [5]. Authors must always make sure it is very clear to readers which ideas and phrases are their own and which are the ideas and phrases of others. This is usually done by citing a reference to any data or conclusions that have already been published by other researchers.
Two kinds of plagiarism are recognized in scientific writing - plagiarism of data and plagiarism of text. The first is where a researcher takes the data, tables or figures from a published paper and uses them, often slightly modified to give some credibility, in his or her own paper, pretending they are his or her own results. Such cases are clearly theft and falsification of data and are regarded as a major breach of research ethics. When such cases are discovered, they carry severe penalties. It is important to distinguish the difference between plagiarism of data-i.e., when one pretends that the data are his or her own - and using the data of others in order to conduct a new analysis, as for example in a systematic review: providing the review gives due acknowledgement of the sources of data. Plagiarism of data is never acceptable; science depends on the integrity of scientists to report their findings in an open and honest way.

Plagiarism of text probably occurs more frequently and for a variety of reasons. There are many situations in which the words used by one author so clearly express a situation that another author uses exactly those words, because he or she cannot think of a better way to describe that situation. Using another writer's words is allowed providing that clear credit is given, usually by putting the quotation in inverted commas and giving the reference - so for example... "When you put your ideas on paper, your instructors want to distinguish between the building block ideas borrowed from other people and your own newly reasoned perspectives or conclusions" [2]. Knowing when and how to use other people's words correctly may be a real problem, especially for a new author and even more especially for those whose native language is 
not English. In one example, in response to an accusation of plagiarism, researchers in Turkey claimed that "using beautiful sentences from other studies on the same subject in our introductions is not unusual" [6] and they did this because they genuinely believed it to be acceptable. The argument is often made that the most important part of a paper is the Results, and while plagiarism of data is totally unacceptable, some degree of plagiarism in the text could be overlooked by editors.

So what would be an acceptable degree of plagiarism? There are different views with some researchers and editors thinking that any form of plagiarism is totally unacceptable, and others taking a more lenient view. The Office of Research Integrity in the USA, an agency that monitors ethical issues in health research, does not regard the use of similar sentences and phrases describing, for example, commonly used methods, a serious breach of publication ethics [1] and most journal editors would agree with this. Especially in the Methods section of a paper, there may be sections of text that greatly resemble text in a number of other papers describing research using the same techniques. There have, however, been examples where an article "was almost entirely stitched together from other scientist's papers" [7] and recently a French researcher happened to read a paper in the Korean Journal of Biological Sciences that he recognized as his own paper published some years before [8] with only slight modifications to make it appear that the research had been carried out in Korea. Clearly these are cases of extreme plagiarism, and clearly in such cases there have to be sanctions - through rejection of the article if the plagiarism is discovered before publication or the publication of a retraction of an article if the plagiarism is discovered only after publication [9]. Because of the potential harm to the reputations and careers of persons involved, and the possibility of litigation that may result, journals are sometimes reluctant to bring an accusation of plagiarism and may find alternative ways of having a paper retracted [10]. In cases where plagiarism has been repeatedly demonstrated, the consequences may include banning the guilty researcher from grant applications, and even suspension or dismissal from a post [11].

The main problem though is not blatant plagiarism, but the occasional use of a phrase or sentence that repeats, word for word, a phrase or sentence published elsewhere. In such cases the editor must ask two questions: Is the plagiarism intentional, and does this seriously undermine the validity of the paper? When plagiarism is repeated within a single paper-e.g., when the author uses several exact or very similar phrases, sentences and even paragraphs from other publications - it would be difficult to accept that this was unintentional. Most editors would also determine that deliberate and repeated plagiarism in different sections of a paper introduces doubts about the reliability of the data being presented. Falsifying the text may be an indication that data are also falsified. Editors take particular note, therefore, of repeated and extensive plagiarism in a paper submitted to them, because such an observation raises doubts about the integrity of the research being reported. As noted previously, editors have a responsibility to the readers of their journal to encourage an ethical approach to research publication; they may therefore refuse publication when the integrity of a paper has been brought into question through evidence of plagiarism in parts of it. Because it is often difficult to detect, the extent of plagiarism in papers submitted for publication is unknown, but a study in the US, examining NIHfunded research projects, suggested that the incidence of misconduct may be as much as 3 cases per 100 scientists per year, with plagiarism accounting for $36 \%$ of these cases of misconduct [12]. The issue may be particularly common where papers are written in languages other than English, since it is much harder to detect plagiarism in a different language. There are those who believe, for example, that because their paper is going to be published in a journal with limited circulation or in a different language, their plagiarism will go undetected by the original authors. The increasing availability of abstracts online and of software designed to detect plagiarism should be a warning that this situation is changing. Software to detect plagiarism was recently applied to about 75,000 abstracts in Medline [13] with the finding that while the number of cases was small $(181,0.2 \%)$ the degree of plagiarism in each case was large. In a majority of the cases detected, the software detected $>85 \%$ correspondence in the words in papers written by different authors, suggesting that where plagiarism was used it was done blatantly with authors copying word for word whole sections of the previously published material. Many journals are now introducing their own policing policies to ensure that plagiarism is detected [13] and that authors who consistently plagiarize pay a severe penalty. The increasing use of systematic reviews, in which publications from many sources, 
including journals with smaller circulation, are subjected to scrutiny, has also unearthed cases of blatant and repeated plagiarism [14].

The JIDC actively discourages any degree of plagiarism. Where the plagiarism is thought to be deliberate, the paper will be rejected and any future submissions from that author would be scrutinized carefully. So how can writers ensure that plagiarism does not enter into their own papers? In the text of a paper, after writing down the main sentences, writers should try to re-write them to give the same information but using different words and then choose the most appropriate version. This is a good exercise in developing the skills of scientific writing, as well as ensuring that the words being used are one's own and not the words of others. Even simple software can help a writer to check his or her own work. Entering the first six words of a sentence into a search engine such as Google, for example, will compare those words with the existing words in the database, which will reveal if those words have been published before. While it may be quite common for a sequence of two or three words to have been used before, a sequence of six identical words would suggest that the sentence should be rewritten. Actively fostering a culture of integrity in one's own research in this way will always help in avoiding instances of misconduct. This is also a good lesson also to pass on to students.

One particular problem is that of "selfplagiarism", that is, using sentences or paragraphs from papers that have already been published under your authorship. This form of plagiarism may occur frequently; in one study five out of nine papers showed significant usage of sentences from papers previously published by the same author on the same subject [15]. Self-plagiarism occurs especially commonly when a researcher applies the "salamitechnique," by writing several papers from the results of a single research project, dividing the data into smaller segments to achieve more publications. Copying whole sentences or even paragraphs from the Introduction and the Methods sections is extremely common in such situations; indeed, this similarity is one way to detect the "salami technique." As with other forms of plagiarism, it is the degree to which the deception is deliberate that is important. Failure to give reference to your own previously published article indicates that you are deliberately trying to pretend the work is new when clearly it is not. Always include appropriate references to your own published work. While you may think that they are your own words so you should be free to use them again, remember that most journals require that any submission made to them must not have been previously published, even if the paper has been published under your name. Moreover, if you have signed over copyright to a journal, the words are no longer yours; they now belong to the journal- and so you are in effect stealing the words that belong to someone else. At the very least, self-plagiarism shows laziness and should be avoided.

Editorial Boards can help by having clear policies on plagiarism, including policies on how to handle cases of apparent plagiarism that are discovered or that are reported to them, and policies on the consequences to an author when a case of plagiarism is demonstrated. The JIDC recognizes that authors from developing countries often have difficulty in expressing their research in the scientific style of writing, and has established a mentorship program specifically to help. We would much rather help you develop your own skills of scientific writing than to receive papers that have "borrowed" the skills of others. The JIDC is committed to upholding the principles of publication ethics, and encourages authors to be conscious of the pitfalls of plagiarism. A paper containing obvious and deliberate plagiarism will be rejected no matter how important the data it presents.

\section{References}

1. Office of Research Integrity. Accessed online at http://ori/dhs/gov/plagiarism.shtml

2. University of North Carolina at Chapel Hill. Plagiarism. Accessed online at http://www.unc.edu/depts/wcweb/handouts/plagiarism. $\underline{\mathrm{html}}$

3. Committee on Publication Ethics Guidelines. Accessed online http://www.publicationethics.org.uk/guidelines

4. Gollogly L, Momen H. Ethical dilemmas in scientific publication: pitfalls and solutions for editors. Revista de Saude Publica 2006:40:24-9 [Medline]

5. The Owl at Purdue. Avoiding Plagiarism. Revision by Karl Stolley, Edited September $30^{\text {th }}$ 2008. Accessed online http://owl.english.purdue.edu/owl/resource/589/01/

6. Yilmaz, I. Plagiarism? No, we're just borrowing better English. Nature 2007;449(7163):658

7. Butler D. Iranian paper sparks sense of déjà-vu. Nature 2008;455(7216):1019

8. Butler D. Entire paper plagiarism caught by software. Nature 2008;455(7214):715

9. Okuyama H, Hirono O, Tamura H, Nishiyama $S$, Takeishi Y, Kayama T, Kubota I. Retraction: Impact of aortic arch stiffness on recurrence of stroke in patients 
with acute ischemic stroke. Circulation Journal 2008;72:1914

10. Gornall J. Journal withdraws paper on grounds of prior publication but avoids issue of plagiarism. British Medical Journal 2007;334:717-20

11. Editorial. Fighting plagiarism. The Lancet 2008;371:2146

12. Titus S, Wells JA, Rhoades LJ. Repairing research integrity. Nature 2008;453(7198):980-82
13. White C. Plagiarism detection system to be launched in June. British Medical Journal 2008;336:797

14. Chalmers I. Role of systematic reviews in detecting plagiarism: case of Asim Kurjak. British Medical Journal 2006;333:594-96

15. Roig M. Re-using text from previously published papers: an exploratory study of potential selfplagiarism. Psychology Reports 2005:97:47-49 